\title{
ZOOPLÂNCTON DO ESTUÁRIO DO RIO SÃO FRANCISCO, NORDESTE DO BRASIL
}

\author{
Sigrid NEUMANN LEITÃO ${ }^{1}$ \\ Marluce Rocha Melo e SOUZA ${ }^{2}$ \\ Fernando de Figueiredo PORTO NETO ${ }^{1}$ \\ Mauro César de Oliveira MOURA ${ }^{1}$ \\ Andréa Pinto SILVA ${ }^{1}$ \\ Lúcia Maria de Oliveira GUSMÃO ${ }^{1}$ \\ ${ }^{1}$ Departamento de Oceanografia da UFPE \\ ${ }^{2}$ IBAMA-SERGIPE
}

\begin{abstract}
RESUMO
Estudos foram realizados no estuário do rio São Francisco, próximo a sede municipal de Brejo Grande, Sergipe (Brasil) em 1997 e 1998, objetivando avaliar os impactos ambientais decorrentes da implantação de inúmeras barragens para geração de energia. Os dados planctônicos foram coletados em duas estações fixas no Baixo São Francisco, uma a montante e outra a jusante da cidade de Brejo Grande. As amostragens foram feitas nos períodos chuvoso (agosto/97) e seco (janeiro/98), a cada 3h, num ciclo completo de marés. A vazão média do rio foi diminuindo de $1993\left(2.592 \mathrm{~m}^{3} \cdot \mathrm{s}^{-1}\right)$ a $1996\left(1.742 \mathrm{~m}^{3} \cdot \mathrm{s}^{-1}\right)$ voltando a aumentar em $1997\left(1.870 \mathrm{~m}^{3} \cdot \mathrm{s}^{-1}\right)$. Menores vazões ocorreram junho/julho e maiores em janeiro, fato associado aos períodos de chuvas a montante do rio, que são no verão. A densidade do zooplâncton foi maior no período seco. O microzooplâncton apresentou 71 taxa, predominando Rotifera com 41 espécies, grupo indicador de regime limnético. Dentre os Rotifera destacaram-se Rotaria sp, Keratella americana, K. cochlearis e Lecane bulla. O mínimo de microzooplâncton foi 468 org. $\mathrm{m}^{-3}$ (preamar, período seco, estação 2) e o máximo foi 3257 org. $\mathrm{m}^{-3}$ (maré secante, período chuvoso, estação 1). O macrozooplâncton foi pobre com apenas 20 taxa, destancando-se Cladocera (6 espécies) seguido por Copepoda (5 espécies). Dentre os Cladocera destacaram-se Moina micrura, Diaphanosoma spinulosum e Bosmina longirostris. $\mathrm{O}$ mínimo foi de 21 org. $\mathrm{m}^{-3} \quad$ (baixa-mar, período chuvoso, estação 2) e o máximo 210 org. $\mathrm{m}^{-3}$ (maré secante, período seco, estação 1) com poucas larvas de crustáceos e peixes. Ficou evidenciado que a maior contribuição zooplanctônica vem do rio São Francisco.
\end{abstract}

Palavras chave: Zooplâncton, estuário, rio São Francisco-Brasil, Tropical

\section{ABSTRACT \\ Zooplankton of the Estuary of the São Francisco River, Northeast Brazil}

Studies were carried out in the estuary of São Francisco river, near Brejo Grande town, Sergipe (Brazil), in 1997 and 1998, in order to evaluate the environmntal impacts Planktonic data were collected in two fixed stations one upstream and other downstream of Brejo Grande town. Samplings were carried out in the rainy (August/97) and dry (January/98) seasons, each 3h, in a complete tidal 
cycle. The planktonic biomass of the microplankton was higher than the macroplankton, although both considered low. The microzooplankton presented 71 taxa, the most diverse Rotifera with 41 species, indicadors of freshwater regime. Among the Rotifera outranked Rotaria sp, Keratella americana, K. cochlearis and Lecane bulla. The minimum microzooplankton was 468 org. $\mathrm{m}^{-3}$ (high tide, dry season, station 2) and the maximum was 3257 org. $\mathrm{m}^{-3}$ (ebb tide, rainy season, station 1). The macrozooplankton presented 20 taxa, the most diverse was Cladocera (6 species) followed by Copepoda (5 species). Among Cladocera outranked Moina micrura, Diaphanosoma spinulosum and Bosmina longirostris. The minimum was 21 org. $\mathrm{m}^{-3}$ (low tide, rainy season, station 2) and the maximum 210 org. $\mathrm{m}^{-3}$ (ebb tide, dry season, station 1) with very few crustacea anf fish larvae. The zooplankton community is highly influenced by the freshwater flux from the São Francisco River.

Key words: Zooplankton, estuary, São Francisco River-BraZil, Tropical

\section{INTRODUÇÃ̃O}

O rio São Francisco está entre os principais ecossistemas naturais no Brasil que têm a estabilidade ecológica ameaçada. Sua área estuarina localizada na região costeira entre os estados de Sergipe e Alagoas, tem sido submetida a diversos impactos além de ser objeto de constantes levantamentos geológicos por se tratar de bacia sedimentar petrolífera de grande interesse à economia nacional. Dentre os impactos que têm afetado a dinâmica estuarina estão as barragens construídas para a geração de energia, a retirada de grandes volumes d'água para a irrigação da agricultura, a carga de esgotos domiciliares e a drenagem de fertilizantes da agroindústria lançados ao longo do rio.

Além disso, a sua desembocadura, tem estado sujeita a intensos processos erosivos no lado do estado de Sergipe e processos deposicionais no estado de Alagoas. Estes processos causam profundas alterações no ecossistema, provocando uma série de danos, muitas vezes irreversíveis, com um acentuado desequilíbrio das características geomorfológicas, físicas, químicas e biológicas, além de prejuízos sócio-econômicos (Souza, 1998).

Visando um acompanhamento das modificações sofridas nos últimos anos na área estuarina do Rio São Francisco, foi elaborada esta pesquisa para avaliar os prejuízos ambientais na área pertencente ao município de Brejo Grande, Sergipe, sendo enfocado neste trabalho o zooplâncton.

A população zooplanctônica, composta de organismos animais, geralmente microscópicos, com curto ciclo de vida e ocupando vários níveis tróficos, respondem rapidamente à condições abióticas reinantes, mostrando-se excelente grupo chave na compreensão da estrutura da comunidade de um ecossistema, principalmente naqueles impactados, através dos seus diversos mecanismos de interações (Levinton, 1995). 


\section{CARACTERIZAÇÃO DA ÁREA}

A área estuarina do rio São Francisco estudada pertence ao Município de Brejo Grande, na microrregião de Propriá, Estado de Sergipe, na posição oriental da Região Nordeste do Brasil. Localiza-se nas seguintes coordenadas geográficas: latitudes de $10^{0} 24^{\prime} 45^{\prime \prime}$ e $10^{\circ} 30^{\prime} 30^{\prime \prime} \mathrm{S}$ e longitudes $36^{\circ} 24^{\prime} 00^{\prime \prime}$ e $36^{0} 30^{\prime} 00^{\prime \prime} \mathrm{W}$ (Figura $1)$.

O clima é do tipo Megatérmico Seco e Semi-Úmido, com uma precipitação pluviométrica média de $1.200 \mathrm{~mm}_{\text {. }} \mathrm{nno}^{-1}$, concentrada nos meses de março a agosto, denominado período chuvoso. A temperatura média anual é de aproximadamente $26^{0} \mathrm{C}$, com mínima de $23^{0} \mathrm{C}$ e máxima de $27^{0} \mathrm{C}$ (Sergipe, 1997). A umidade relativa do ar é geralmente maior que $80 \%$ e evaporação média anual de $170 \mathrm{~mm}$. Os ventos predominantes são de Sudeste, com variação de Leste e Nordeste, constituintes da Massa Equatorial Atlântica e com velocidade média em torno de $2,5 \mathrm{~m} \cdot \mathrm{s}^{-1}$ (Andrade e Lins, 1971).

A região faz parte da Bacia Sedimentar de Sergipe e Alagoas, sendo recobertas pelo grupo Barreiras e pelos Aluviões e Sedimentos de Praias. Esta bacia com a do Recôncavo e com a Fossa de Tucano e Jatobá formam a Província Costeira, cujas feições fisiográficas são formadas pela rede de drenagem e pela uniformidade tabular do relevo, além das planícies fluviomarinhas e marinhas que se estendem por todo o litoral da área. O padrão de drenagem é dendrítico, com variações paralela e subparalela. As planícies comportam várzeas alagadiças, brejos e lagunas (Sergipe, 1993).

A foz do rio São Francisco é formada por feições deltaicas altamente destrutivas, dominadas por ondas. Essas feições são constituídas por depósitos associados a terraços marinhos, terraços fluviais, pântanos, mangues e lagunas. São encontrados também depósitos do tipo leques aluviais coalescentes, bem como importantes campos de dunas. São também encontradas, em quase toda a parte externa, duas gerações de dunas; uma mais interna, subatual e já povoada pela vegetação, e outra externa, com dunas em franco desenvolvimento, que cobrem em parte a primeira. Essas dunas podem atingir altitudes de até 30m (Dominguez et al, 1981).

Em regiões protegidas sob a influência das marés, como nas partes inferiores dos vales entalhados na Formação Barreiras e em algumas zonas baixas, entre os terraços marinhos pleistocênico e holocênico, são encontrados manguezais, com substratos constituídos predominantemente de materiais argilo-siltosos, ricos em matéria orgânica (Bittencourt et al., 1983).

A área apresenta solos hidromórficos, podsol, areias marinhas quartizosas e solos indiscriminados de mangues (Sergipe, 1997).

O rio São Francisco nasce na Serra da Canastra em Minas Gerais e percorre $3.100 \mathrm{~km}$, desde a nascente até a foz, no Oceano Atlântico, que fica entre os municípios de Brejo Grande, em Sergipe, e Piaçabuçu, em Alagoas. Drena uma bacia hidrográfica de aproximadamente $640.000 \mathrm{~km}^{2}$ (CODEVASF, 1996). Sua bacia superior está localizada em uma região tropical úmida, enquanto a parte média 
encontra-se no "polígono da seca", na região semi-árida do Nordeste, antes de o rio cruzar a faixa costeira úmida e entrar no Oceano Atlântico (Coutinho, 1967/69).

$\mathrm{Na}$ desembocadura do rio São Francisco, a temperatura média da água superficial é de $26^{\circ} \mathrm{C}$ e a salinidade varia de 23 a 32\%o (Cavalcanti et al, 1965/66).

A cobertura vegetal varia desde os campos secos e/ou inundáveis até os complexos de restinga e mangues. As lavouras predominantes são o coco-da-baía, a mandioca, e alguns poucos cultivos de subsistência. Há nas várzeas grandes áreas de plantações de arroz. Existem ainda pastos naturais e plantados Os manguezais estão em áreas protegidas da costa, principalmente em canais que separam ilhas do continente; são representados pelas espécies Rhizophora mangle, Laguncularia racemosa, Avicennia germinans, Avicennia schaueriana e Conocapus erectus (ADEMA, 1984a; Sergipe, 1993).

Entre as microalgas do plâncton destacam-se as diatomáceas, principalmente os gêneros Nitzchia, Surirella, Pinnularia, Navicula, Eunotia e Cocconeis. Das cianofíceas destacou-se Oscillatoria e das clorofíceas, Penium (Sergipe, 1993).

A fauna é bastante diversificada; encontram-se, sobretudo, moluscos, crustáceos e peixes. A espécie de maior importância alimentar e que também constitui numa fonte de renda, devido ao seu tradicional consumo é o caranguejouçá (Ucides cordatus), que vive nas tocas na lama (ADEMA, 1984b). O camarão sete-barbas (Xiphopenaeus kroieri) também se destaca na economia da área. Os moluscos estão representados pela ostra (Crassostrea rhizophorae) e pelo sururu (Mytella sp), que diminuíram em densidade, nos últimos anos. Entre os peixes há tainhas (Mugil curema), carapebas (Eugerres spp), camurins (Centropomus undecimalis), bagres (Tachysurus lunycuties, Tachysurus spp) curimã (Mugil brasiliensis). O zooplâncton está composto por Protozoa, Cladocera e Rotifera, entre outros (Sergipe, 1993). Grande número de aves de arribação surgem em determinadas épocas do ano, quando do período migratório.

A economia da região se baseia quase que exclusivamente na produção de alimentos, sendo as ocupações mais significativas a agricultura e a pesca (Sergipe, 1993).

Segundo o mapeamento de cadastramento, realizado em 1997 pela Prefeitura de Brejo Grande para o Programa Agentes Comunitários de Saúde (PACS), existem na área do lado do Estado de Sergipe uma cidade (com 1.043 famílias), 8 povoados (com 823 famílias), 2 sítios (com 20 famílias) e 6 fazendas (23 famílias); todos os locais dependem diretamente do rio São Francisco.

O Município de Brejo Grande possui uma população de 6813 habitantes, sendo 3.747, na zona urbana e 3.066, na zona rural (IBGE, 1997). Cerca de $42 \%$ da população é alfabetizada, entretanto a maioria tem apenas o $1^{\circ}$ grau menor. Com relação ao uso e escoamento de instalação sanitária, apenas 35\% dos domicílios apresenta fossa rudimentar, enquanto $65 \%$ lança seus dejetos diretamente no rio sem qualquer tratamento. Quanto ao lixo, 78,95\% é jogado em terreno baldio (Sergipe, 1997a). A maioria destes dejetos líquidos e sólidos terminam carreados para a zona estuarina, contaminando a água. 
De acordo com Melo (1996), entre os usos mais significativos do rio São Francisco, para as populações ribeirinhas, está em primeiro lugar a pesca, conforme $31,65 \%$ dos entrevistados. Em segundo, o plantio de arroz, com 21,10\%, seguido da água para consumo com $20,60 \%$ das respostas dadas.

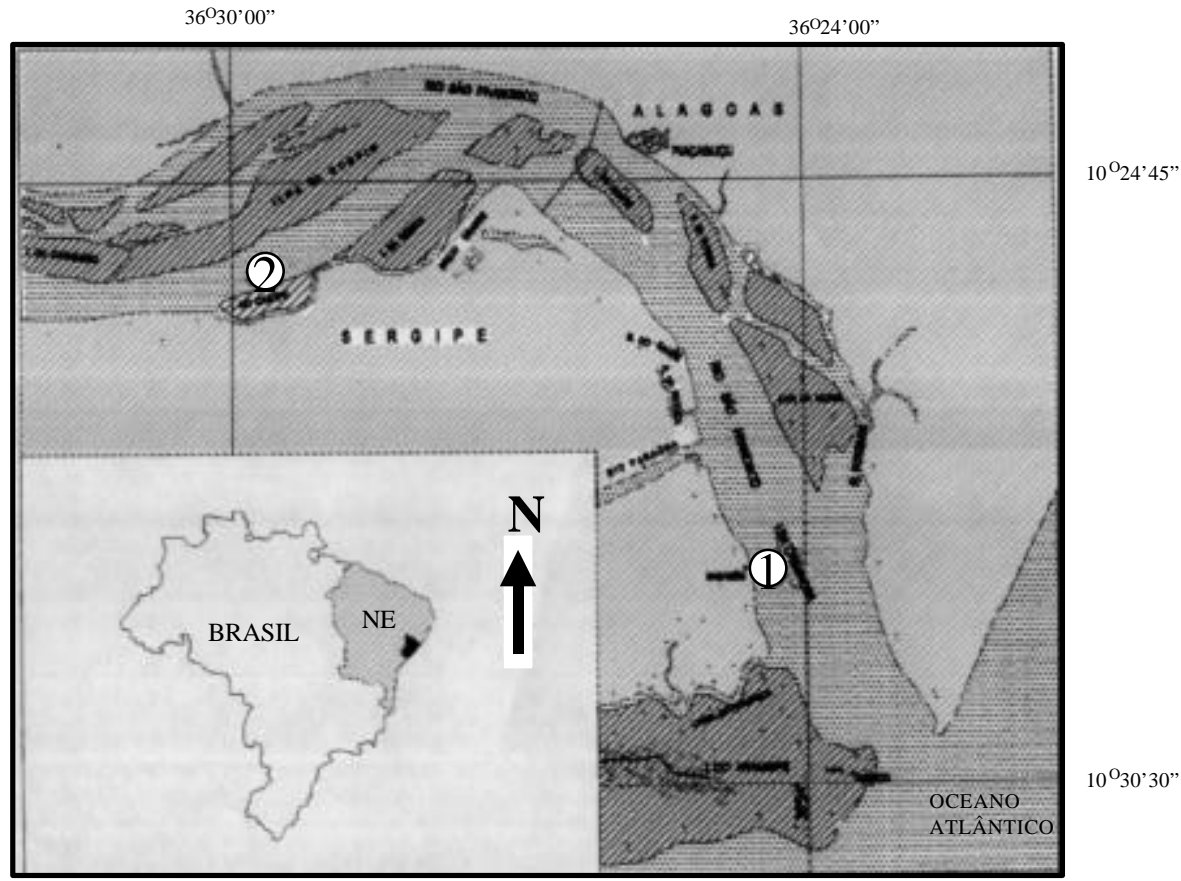

Figura 1 - Localização da área do estuário do Rio São Francisco, em Brejo Grande, Sergipe (Brasil) e das estações de coleta.

\section{MATERIAL E MÉTODOS}

A estratégia metodológica consistiu em coletar dados planctonológicos na área estuarina do rio São Francisco, no Município de Brejo Grande, Sergipe.

Os dados foram obtidos em duas estações fixas localizadas no estuário do rio São Francisco, uma a montante e outra a jusante da sede municipal de Brejo Grande (Figura 1). As amostragens foram feitas em agosto/1997 (período chuvoso) e janeiro/1998 (período seco), a cada 3 horas, num ciclo de 12 horas, com o auxílio de duas redes de plâncton, cada uma com $1 \mathrm{~m}$ de comprimento, $30 \mathrm{~cm}$ de diâmetro de boca, sendo uma com $65 \mu \mathrm{m}$ e outra com $300 \mu \mathrm{m}$ de abertura de malha. Essas redes foram arrastadas horizontalmente à superfície por 5 minutos, com o barco em 
velocidade lenta e constante. Após as coletas, as amostras foram fixadas com formol neutro a $4 \%$.

Em laboratório, procedeu-se a análise qualiquantitativa do microzooplâncton, tendo-se retirado $1 \mathrm{ml}$ da amostra e colocado em lâmina tipo Sedgwick-Rafter e analisada sob microscópio composto. Para o macrozooplâncton foram retirados $4 \mathrm{ml}$ da amostra, colocados em placa de Petri quadriculada $(0,5 \mathrm{~cm})$ e analisada sob Estereomicroscópio. Na identificação das espécies foram utilizadas, entre outras, as obras de: Trégouboff e Rose (1957), Mizuno (1968), Koste (1978) e Boltovskoy (1981).

\section{RESULTADOS}

\section{Microzooplâncton}

Foram registrados 71 taxa (Tabelas 1 e 2), destacando-se Rotifera com 41 espécies, seguida por Copepoda (7 espécies) e Cladocera (6 espécies). Houve um nítido predomínio de espécies de origem limnética. Foram registrados 58 taxa para o período chuvoso e 54 taxa para o período seco.

No tocante à abundância relativa, Rotifera predominou em quase todas as amostras (Figura 2). Protozoa foi também representativo, principalmente nas baixa mares, enquanto Copepoda, nas preamares e Cladocera, na maré secante do período chuvoso (Figura 2).

Quanto à frequiência de ocorrência, no período chuvoso foram representativos com mais de $80 \%$ Centropyxis acureata, Rotaria sp, náuplios de Copepoda, Arcella vulgaris, Keratella americana, Lecane bulla e Bosminopsis deitersi (Figura 3). No período seco apresentaram mais de $80 \%$ de frequiência de ocorrência Rotaria sp, Keratella americana, K. cochlearis, Ostracoda, Diaphanosoma spinulosum, Bosminopsis deitersi, Notodiaptomus sp e Thermocyclops decipiens e náuplios de Copepoda (Figura 4).

Quantitativamente, o menor valor foi de 468org. $\mathrm{m}^{-3}$, na preamar do período seco, na estação 2 e o maior valor foi $3.257 \mathrm{org} . \mathrm{m}^{-3}$, na maré secante do período chuvoso, na estação 1 (Figura 5). Este maior valor foi decorrente do predomínio do Cladocera Bosminopsis deitersi $\left(774\right.$ org. $\mathrm{m}^{-3}$ ) e do Rotifera Rotaria sp (468 org. $\mathrm{m}^{-3}$ ). É interessante observar que no período chuvoso existe a tendência de um ciclo definido na variação diurna, com valores quantitativos que podem aumentar da maré secante à preamar; isso ocorre em ambas as estações, exceto na maré secante da estação 1, quando se registraram grandes quantidades de Cladocera e Rotifera. No período seco, o ciclo de variação diurna foi inverso, decrescendo da maré secante à preamar.

Estes dados quantitativos indicam que a maior contribuição vem do rio São Francisco. A influência marinha na área é pequena, pelo menos nas estações amostradas, fato evidenciado pela pouca representatividade de espécies planctônicas marinhas eurialinas. 
Tabela 1 - Variação quantitativa do microzooplâncton (org. $\mathrm{m}^{-3}$ ) do sistema estuarino do Rio São Francisco em Brejo Grande, Sergipe, em 04 e 05/08/97 (período chuvoso).

\begin{tabular}{|c|c|c|c|c|c|c|c|c|}
\hline ESTAÇÃO & & 1 & & & & 2 & & \\
\hline MARÉS & MS & $\mathrm{BM}$ & ME & PM & MS & $\mathrm{BM}$ & ME & PM \\
\hline $\begin{array}{l}\text { Arcella vulgaris } \text { Ehrenberg, } 1838 \\
\text { Arcella dentata } \text { Ehrenberg, } 1838\end{array}$ & 90 & 36 & 36 & 18 & 90 & 18 & $\begin{array}{l}72 \\
18\end{array}$ & 180 \\
\hline Centropyxis acureata Stein, 1840 & 90 & 90 & 108 & 54 & 36 & 252 & 198 & 36 \\
\hline Tetromphallus bulloides d'Orbigny, 1826 & & & 18 & 18 & & & & 36 \\
\hline Tintinnopis sp & & 18 & 18 & & & & & \\
\hline Codonella sp & & 18 & & & & & & \\
\hline Nematoda & 18 & & 18 & 36 & & 18 & & \\
\hline Rotaria rotatoria (Pallas, 1766) & 36 & & & & & & & \\
\hline Rotaria sp & 468 & 180 & 108 & 126 & 54 & 36 & 126 & 180 \\
\hline Epiphanes macrourus(Barrois\&Daday, 1894) & 53 & & & & & 18 & & \\
\hline Platyias quadricornis (Ehrenberg, 1832) & & & & & & & & 18 \\
\hline Brachionus patulus (O.F.Müller,1786) & 18 & & & 18 & & & & \\
\hline Brachionus quadridentatus (Daday, 1897) & 18 & & & 18 & & & & \\
\hline Brachionuscaudatus Barrois \&Daday, 1894 & 18 & 18 & & & & 18 & 18 & 36 \\
\hline Brachionus angularis Gosse, 1851 & 36 & & & & & 18 & & 36 \\
\hline Brachionus falcatus Zacharias, 1898 & 18 & 54 & & 18 & & 18 & & 18 \\
\hline Brachionus plicatilis (O.F.Müller,1786) & 18 & & 36 & & 36 & 54 & 18 & \\
\hline Brachionus havanensis Rousselet, 1911 & 36 & & & & & 18 & & \\
\hline Keratella americana Carlin, 1943 & 54 & & 36 & 54 & 54 & 36 & 36 & 90 \\
\hline Keratella cochlearis (Gosse, 1851) & 54 & 18 & 54 & & 36 & 36 & & 18 \\
\hline Keratella tropica (Apstein, 1907) & 72 & & 36 & 36 & & & 18 & 18 \\
\hline Ploesoma truncatum (Levander, 1894) & & & & 18 & & & & \\
\hline Mytilina ventralis (Ehrenberg, 1832) & 36 & & & & & & & 18 \\
\hline Macrochaetus collinsi (Gosse, 1867) & 18 & & & & & & & 18 \\
\hline Anuraeopsis sp & & & 18 & & & & & 18 \\
\hline Lepadella ovalis (O.F. Müller, 1786) & & & & & & 18 & & \\
\hline Lecane curvicornis (Murray, 1913) & 18 & & 36 & & & & & \\
\hline Lecane papuana (Murray, 1913) & & & & & & 18 & & 36 \\
\hline Lecane stichaea Harring, 1913 & 18 & & & & & & & \\
\hline Lecane leontina (Turner, 1892) & 18 & & & & & & & 18 \\
\hline Lecane lunaris (Ehrenberg, 1832) & 18 & & & & & & & \\
\hline Lecane bulla (Gosse, 1886) & 180 & 18 & 90 & 72 & 36 & & 180 & 162 \\
\hline Euchlanis dilatata Ehrenberg, 1832 & & & & 18 & & 18 & & 108 \\
\hline Trichocerca $\mathrm{sp}$ & & & & 18 & & & & \\
\hline Polyarthra vulgaris Carlin, 1943 & & & & 18 & 18 & & & \\
\hline Synchaeta sp & & & & & 18 & & & \\
\hline Collotheca sp & & & & & & & & 18 \\
\hline Testudinella patina (Hermann, 1783) & 18 & & 18 & & 18 & & 36 & \\
\hline Testudinella $\mathrm{sp}$ & & & & & & 18 & & \\
\hline Filinia longiseta (Ehrenberg, 1834) & 18 & 18 & 36 & & & & & \\
\hline Gastropoda véliger & 18 & 72 & & 36 & & & & 54 \\
\hline Bivalvia véliger & & & 36 & 18 & & & & 36 \\
\hline Ostracoda & 54 & 18 & 18 & & & 18 & & \\
\hline Bosminopsis deitersi Richard, 1895 & 774 & 18 & 54 & 270 & 18 & & 90 & 18 \\
\hline Bosmina longirostris (O.F. Müller, 1785) & 90 & & 36 & & 18 & 36 & 18 & 18 \\
\hline Ceriodaphnia cornuta Sars, 1886 & 36 & & 18 & & & & & \\
\hline Diaphanosoma spinulosum Herst, 1975 & 108 & & & & 54 & & & \\
\hline Moina micrura & 162 & & 72 & 72 & 36 & & & \\
\hline Chydoridae & 36 & & 18 & & 18 & & & \\
\hline Paracalanus crassirostris F.Dahl, 1894 & & & & 36 & & & & \\
\hline Pseudodiaptomus marshi Wright, 1936 & & 18 & & & & & & \\
\hline Notodiaptomus sp & 54 & 18 & 18 & 54 & 18 & 18 & & \\
\hline Oithona oswaldocruzi Oliveira, 1945 & 18 & & & & & & & \\
\hline Thermocyclops decipiens Kiefer, 1929 & 144 & 90 & 36 & & & 18 & 36 & 36 \\
\hline Nitokra sp & & 18 & 18 & & & & & \\
\hline Copepoda náuplios & 324 & 18 & 234 & 342 & 126 & 36 & 180 & 234 \\
\hline Penaeidae larva & & & 18 & & & & & \\
\hline Insecta larva & & & 18 & & & 36 & & 36 \\
\hline TOTAL & 3257 & 738 & 1260 & 1368 & 684 & 774 & 1044 & 1494 \\
\hline
\end{tabular}


Tabela 2 - Variação quantitativa (org. $\mathrm{m}^{-3}$ ) do microzooplâncton do sistema estuarino do Rio São Francisco em Brejo Grande, Sergipe, em 12 e 13/01/98 (período seco).

\begin{tabular}{|c|c|c|c|c|c|c|c|c|}
\hline ESTAÇÃO & & 1 & & & & 2 & & \\
\hline MARÉS & MS & BM & $\mathrm{ME}$ & PM & MS & $\mathrm{BM}$ & $\mathrm{ME}$ & PM \\
\hline Arcella vulgaris Ehrenberg, 1838 & 144 & 234 & & & 162 & 90 & 162 & \\
\hline Arcella dentata Ehrenberg, 1838 & 18 & & & & & & & \\
\hline Centropyxis acureata Stein, 1840 & 72 & 162 & 72 & & 54 & & 72 & \\
\hline Tintinnopis sp & 18 & & & & & & & \\
\hline Hydromedusae & & 18 & & & & & & \\
\hline Nematoda & 18 & & & & & & & \\
\hline Rotaria rotatoria (Pallas, 1766) & & 36 & & & 36 & 36 & 18 & \\
\hline Rotaria $s p$ & 36 & 108 & 162 & 18 & 18 & 72 & 36 & 72 \\
\hline Epiphanesmacrourus (Bamois\&Daday, 1894) & & & 126 & & 18 & & & 18 \\
\hline Platyias quadricornis (Ehrenberg, 1832) & & & & & 18 & & & 18 \\
\hline Brachionus patulus (O. F. Müller, 1786) & 18 & 18 & 18 & & & & & \\
\hline Brachionus quadridentatus (Daday, 1897) & & 18 & & & 18 & & 36 & \\
\hline Brachionus calycifloruus Pallas, 1766 & & & & & & & & 18 \\
\hline Brachionus dolabratus Ehrenberg, 1832 & & & & & 72 & & 36 & \\
\hline Keratella americana Carlin, 1943 & 180 & 108 & 216 & 54 & 558 & 288 & 270 & 36 \\
\hline Keratella cochlearis (Gosse, 1851) & 468 & 522 & 270 & 180 & 414 & 162 & 216 & 90 \\
\hline Ploesoma truncatum (Levander, 1894) & & & & & & & 18 & \\
\hline Mytilina ventralis (Ehrenberg, 1832) & & & & & & & 18 & \\
\hline Lepadella ovalis (O.F.Müller, 1786) & & & 18 & & & & & \\
\hline Lecane curvicornis (Murray, 1913) & & & & 18 & 18 & & 18 & \\
\hline Lecane papuana (Murray, 1913) & & & & & & 18 & & \\
\hline Lecane ludwigi (Eckstein, 1893) & & & & & 18 & & & \\
\hline Lecane lunaris (Ehrenberg, 1832) & & & & 18 & & & & \\
\hline Lecane bulla (Gosse, 1886) & & 36 & & & & 18 & 36 & \\
\hline Lecane luna (O. F. Müller, 1776) & & & & & & 18 & & \\
\hline Euchlanis dilatata Ehrenberg, 1832 & & 18 & & & 36 & & & \\
\hline Cephallodella $\mathrm{sp}$ & 18 & 18 & & & & 18 & 18 & \\
\hline Trichocerca sp & & & & & & & 18 & 18 \\
\hline Asplanchna sp & & 18 & & & & 18 & & \\
\hline Collotheca sp & & & & & & & & 18 \\
\hline Testudinella patina (Hermann, 1783) & & & & & 36 & 18 & 54 & \\
\hline Ptygura sp & & & 180 & & 18 & & & \\
\hline Filinia longiseta (Ehrenberg, 1834) & & & & & & & & 36 \\
\hline Filinia opoliensis (Ehrenberg, 1834) & & & & & 18 & & & \\
\hline Gastropoda véliger & 36 & 108 & 90 & & & & & \\
\hline Bivalvia véliger & & & & & 18 & & & \\
\hline Polychaeta (larvas) & 36 & & & 72 & 18 & & & \\
\hline Ostracoda & 126 & 198 & 90 & 90 & 180 & 486 & 54 & 18 \\
\hline Bosminopsis deitersi Richard, 1895 & 36 & 18 & 36 & 18 & 72 & 54 & 54 & \\
\hline Bosmina longirostris (O.F. Müller, 1785) & 18 & 18 & & & 18 & 18 & 36 & \\
\hline Ceriodaphnia cornuta Sars, 1886 & & & & & & & 18 & \\
\hline Diaphanosoma spinulosum Herst, 1975 & 36 & 36 & 18 & 18 & 18 & 108 & 36 & 18 \\
\hline Moina micrura Kurtz, 1874 & 18 & 72 & & 36 & 90 & 18 & & 18 \\
\hline Chydoridae & & 18 & & & 18 & & 18 & \\
\hline Notodiaptomus sp & 54 & 18 & 54 & 90 & 36 & 54 & 36 & \\
\hline Oithona oswaldocruzi Oliveira, 1945 & & & & & 54 & & & \\
\hline Halicyclops oraeeburnensis Lindberg, 1957 & & & & 18 & & & & \\
\hline Thermocyclops decipiens Kiefer, 1929 & 36 & 18 & 18 & 54 & 36 & 54 & & 18 \\
\hline Nitokra $\mathrm{sp}$ & & & & 18 & & & & \\
\hline Copepoda náuplios & 360 & 306 & 216 & 144 & 360 & 270 & 54 & 54 \\
\hline Penaeidae larva & & & & & 18 & 18 & & \\
\hline Caridea zoea & & & 18 & & & & & \\
\hline Insecta larva & & 18 & 18 & & 18 & 18 & 36 & \\
\hline Pisces larva & & & & & 18 & & & 18 \\
\hline TOTAL & 1746 & 2142 & 1620 & 846 & 2484 & 1854 & 1368 & 468 \\
\hline
\end{tabular}



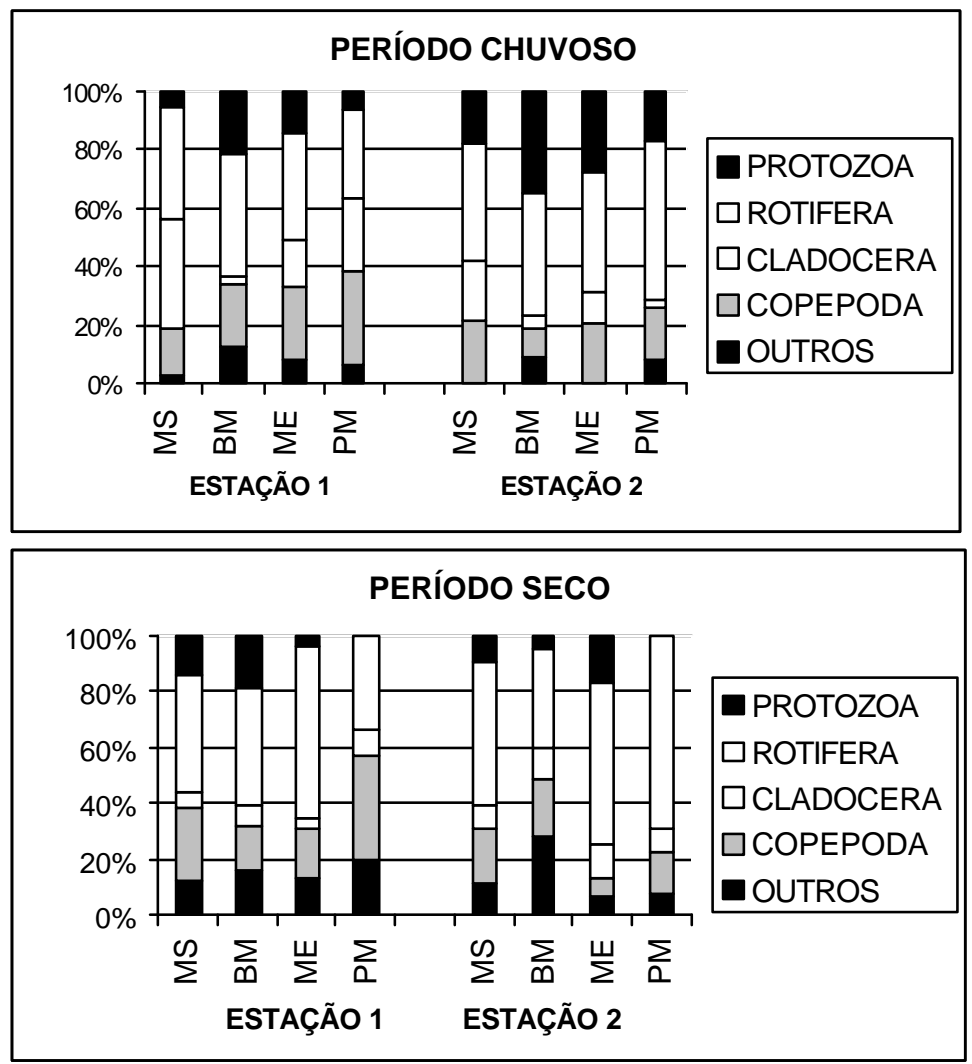

Figura 2 - Abundância relativa do microzooplâncton do rio São Francisco, em Brejo Grande, Sergipe, em 04 e 05/08/97 (período chuvoso) e em 12 e 13/01/98 (período seco). 


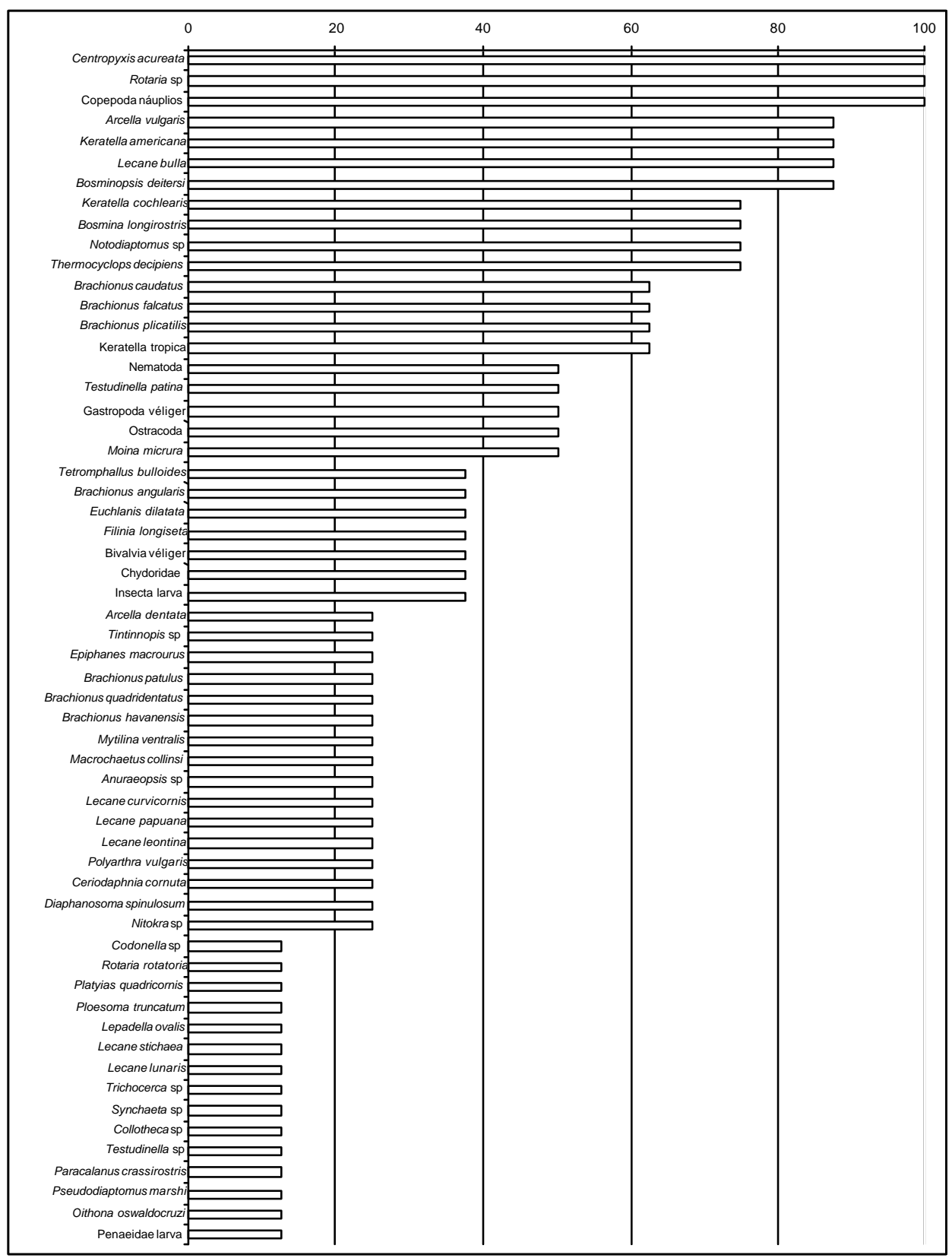

Figura 3 - Frequiência de ocorrência do microzooplâncton no sistema estuarino do Rio São Francisco, em Brejo Grande, Sergipe, em 04 e 05/08/97 (período chuvoso). 


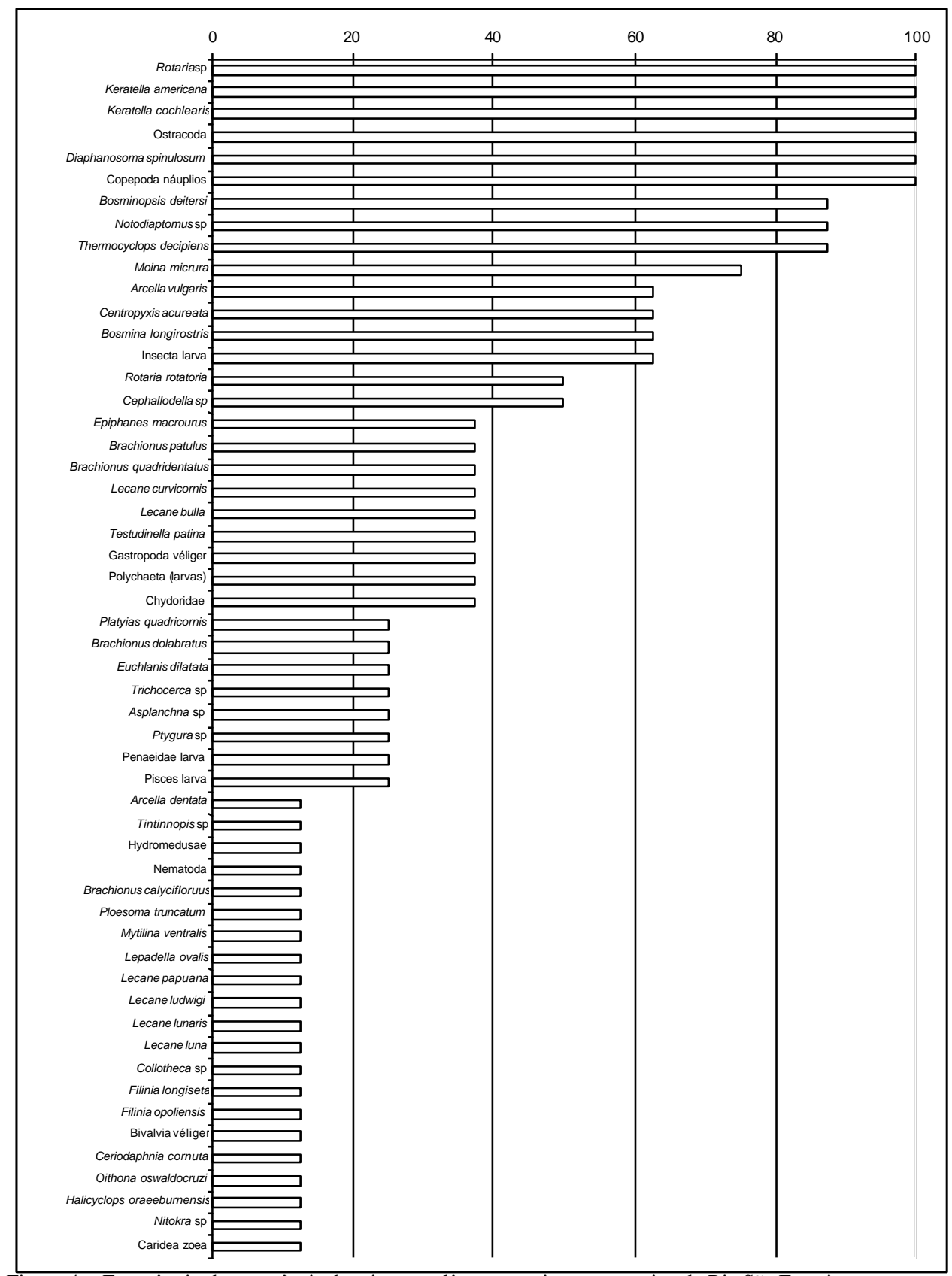

Figura 4 - Frequiência de ocorrência do microzooplâncton no sistema estuarino do Rio São Francisco, em Brejo Grande, Sergipe, em 12 e 13/01/98 (período seco).

Trab. Oceanog. Univ. Fed. PE, Recife, 27(1): 33-54, 1999. 


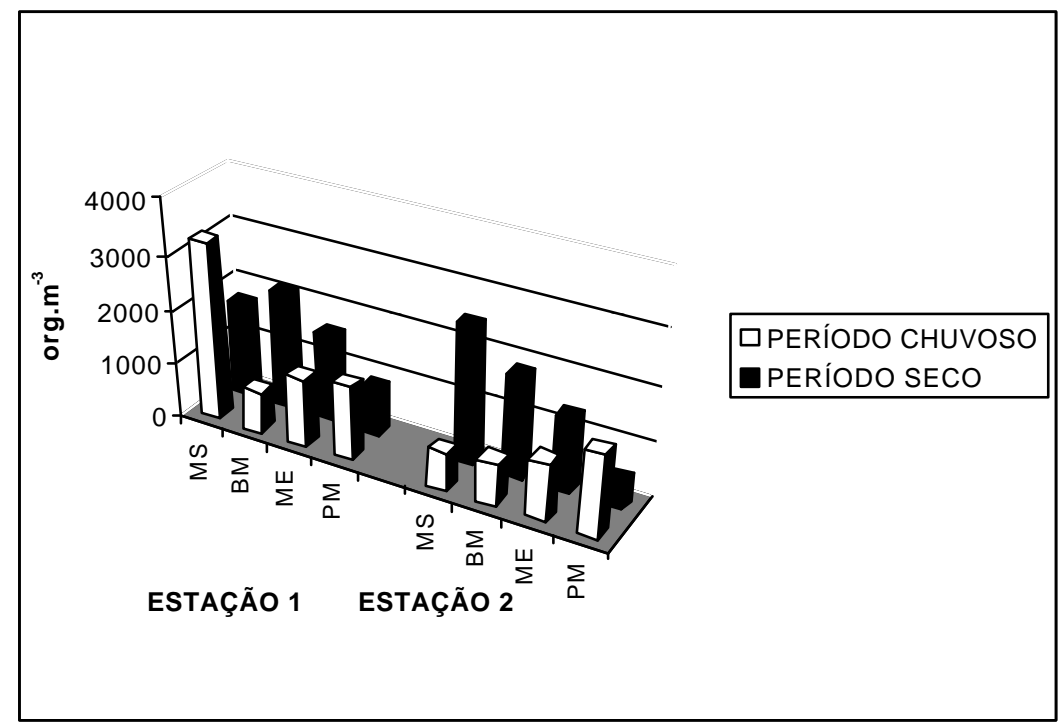

Figura 5 - Variação quantitativa total do microzooplâncton no sistema estuarino do Rio São Francisco, em Brejo Grande, Sergipe em 04 e 05/08/97 (período chuvoso) e 12 e 13/01/98 (período seco).

\section{Macrozooplâncton}

O macrozooplâncton esteve representado por 20 taxa pertencentes aos filos Mollusca, Crustacea (Cladocera, Copepoda, Ostracoda, Isopoda e Decapoda, In secta e Chordata (Pisces); sendo que Mollusca, Isopoda, Decapoda, Insecta e Pisces ocorreram apenas no estágio larval (Tabelas 3 e 4). Destacou-se em número de espécies, Cladocera (6 espécies) seguido por Copepoda, (5 espécies).

Em termos de abundância relativa, no período chuvoso, destacou-se Copepoda, na maré secante, na preamar da estação 1, na maré enchente e preamar da estação 2. As larvas de Crustacea foram representativas nas baixa-mares de ambas as estações, enquanto os veligéres de Mollusca se destacaram na maré enchente da estação 1. Cladocera foi significativa em todas as marés da estação 2. No período seco, destacou-se Cladocera, nas marés secante e enchente e baixa-mares das duas estações, seguida por Copepoda. Este último grupo foi mais representativo na preamar (Figura 6)

Quanto à frequiência de ocorrência, no período chuvoso, destacaram-se com mais de 70\% Moina micrura, Notodiaptomus sp e Bosmina longirostris (Figura 7). No período seco apresentaram mais de $70 \%$ de freqüência de ocorrência Diaphanosoma spinulosum, Moina micrura e Notodiaptomus sp (Figura 8).

Quantitativamente, o período seco (média de 103,25org. $\mathrm{m}^{-3}$ ) foi bem mais rico do que o período chuvoso (média de $53,25 \mathrm{org} . \mathrm{m}^{-3}$ ). Foi observada a diferença 
entre as estações de coleta, apenas no período chuvoso, quando a estação 1 apresentou o dobro da quantidade de organismos. O mínimo foi de $21 \mathrm{org}^{-3} \mathrm{~m}^{-3}$, na baixa-mar do período chuvoso, na estação 2 e o máximo foi de $210 \mathrm{org} \cdot \mathrm{m}^{-3}$, na maré secante do período seco, na estação 1 (Figura 9) (Tabelas 3 e 4).

Tabela 3- Variação quantitativa do macrozooplâncton (org. $\mathrm{m}^{-3}$ ) do rio São Francisco, em Brejo Grande, Sergipe, em 04 e 05/08/97 (período chuvoso). MS=maré secante, BM=baixa-mar, ME=maré enchente, $\mathrm{PM}=$ preamar

\begin{tabular}{|c|c|c|c|c|c|c|c|c|}
\hline ESTAÇÕES & & & & & & & & \\
\hline TÁXONS & MS & $\mathrm{BM}$ & ME & PM & MS & $\mathrm{BM}$ & ME & PM \\
\hline $\begin{array}{l}\text { Bivalvia véliger } \\
\text { Gastropoda véliger }\end{array}$ & 3 & 3 & 36 & 3 & & & & $\begin{array}{l}6 \\
9\end{array}$ \\
\hline Diaphanosoma spinulosum Herst, 1975 & & & & & 6 & & & \\
\hline Moina micrura Kurtz, 1874 & 9 & 9 & 6 & 15 & 15 & 6 & 9 & 9 \\
\hline Bosmina longirostris (O.F. Müller, 1785) & & 3 & 12 & 3 & & 6 & 3 & 6 \\
\hline Bosminopsis deitersi Richard, 1895 & 3 & 6 & & & & & & \\
\hline Alonella $\mathrm{sp}$ & & & & & & & 6 & \\
\hline Pseudodiaptomus marshi Wright, $\underline{1936}$ & & & & 9 & & & & 9 \\
\hline Notodiaptomus $\mathrm{sp}$ & 39 & 6 & 27 & 42 & 9 & 3 & 6 & 6 \\
\hline Thermocyclops decipiens $\underline{\text { Kiefer }, 1929}$ & & 6 & & 3 & & & & \\
\hline Penaeidae larva & & & & 3 & & & & \\
\hline Brachyura zoea & & 18 & 9 & 3 & 21 & & & \\
\hline Caridea larva & & 3 & 3 & & & 6 & & \\
\hline Insecta larva & & & 3 & & & & & \\
\hline TOTAL & 54 & 54 & 96 & 81 & 51 & 21 & 24 & 45 \\
\hline
\end{tabular}

Tabela 4 - Variação quantitativa do macrozooplâncton (org. $\mathrm{m}^{-3}$ ) do rio São Francisco, em Brejo Grande, Sergipe, em 12 e 13/01/98 (período seco). MS=maré secante, $\mathrm{BM}=$ baixa-mar, ME=maré enchente, $\mathrm{PM}=$ preamar

\begin{tabular}{|c|c|c|c|c|c|c|c|c|}
\hline ESTAÇÕES & & 1 & & & & 2 & & \\
\hline TÁXONS & MS & $\mathrm{BM}$ & ME & $\mathrm{PM}$ & MS & $\mathrm{BM}$ & ME & $\mathrm{PM}$ \\
\hline Bivalvia véliger & 3 & 3 & & & 9 & 6 & & 3 \\
\hline Gastropoda véliger & & & & & 3 & & & 3 \\
\hline Diaphanosoma spinulosum $\underline{\text { Herst }}, \underline{1975}$ & 48 & 30 & 9 & 3 & 24 & 30 & 39 & 6 \\
\hline Ceriodaphnia cornuta Sars, 1886 & 15 & & & & 6 & 3 & 6 & \\
\hline Moina micrura Kurtz, 1874 & 39 & 27 & 6 & 6 & 78 & 27 & 36 & 9 \\
\hline Bosmina longirostris (O.F. Müller, 1785) & 6 & & 3 & & & 3 & & \\
\hline Bosminopsis deitersi Richard, 1895 & & & 3 & & & 3 & & \\
\hline Alonella sp & & 3 & & & & & & \\
\hline Ostracoda & & 3 & & & 6 & 3 & 3 & \\
\hline 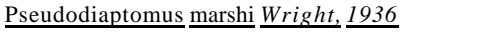 & 51 & 3 & & 33 & 6 & & & 12 \\
\hline Notodiaptomus $\mathrm{sp}$ & 27 & 15 & 9 & 12 & 24 & 12 & 15 & \\
\hline Oithona oswaldocruzi Oliveira, $\underline{1945}$ & & & & & & & & 3 \\
\hline Thermocyclops decipiens Kiefer,1929 & & & & & & & 3 & \\
\hline Harpacticoida & 3 & & & & & & & \\
\hline Isopoda larva & 3 & & & & & & & \\
\hline Penaeidae larva & & & & & & 3 & 6 & 6 \\
\hline Brachyura zoea & & 6 & & 3 & 6 & 9 & & \\
\hline Caridea larva & 9 & & 3 & & 12 & 3 & 1 & \\
\hline Insecta larva & 6 & 3 & 3 & & & & & \\
\hline Pisces larva & & & & 3 & & & & \\
\hline TOTAL & 210 & 93 & 36 & 60 & 174 & 102 & 109 & 42 \\
\hline
\end{tabular}




\section{PERÍODO CHUVOSO}

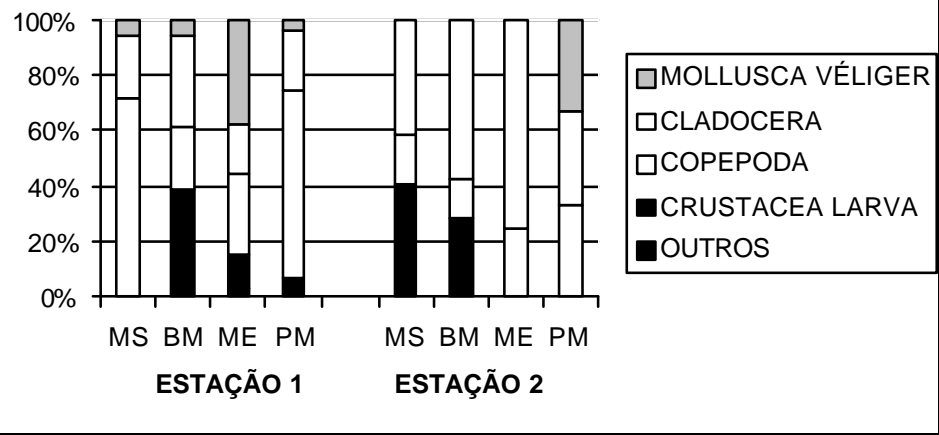

\section{PERÍODO SECO}

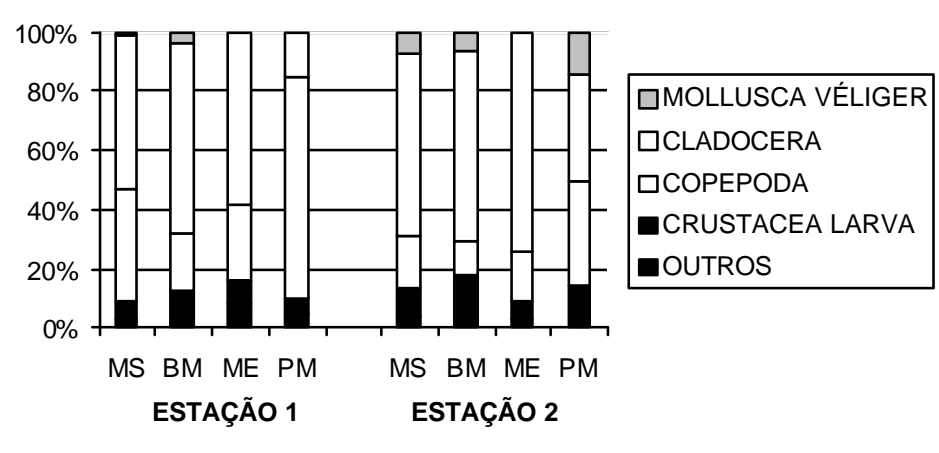

Figura 6 - Abundância relativa do macrozooplâncton do Rio São Francisco, em Brejo Grande, Sergipe, em 04 e 05/08/97 (período chuvoso) e em 12 e 13/01/98 (período seco). 


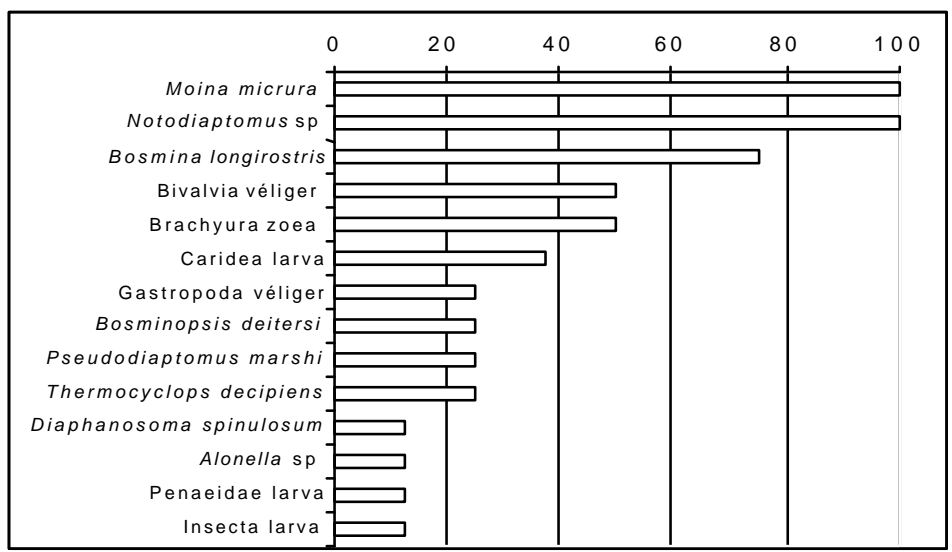

Figura 7 - Freqüência de ocorrência do macrozooplâncton no sistema estuarino do Rio São Francisco, em Brejo Grande, Sergipe, em 04 e 05/08/97 (período chuvoso).

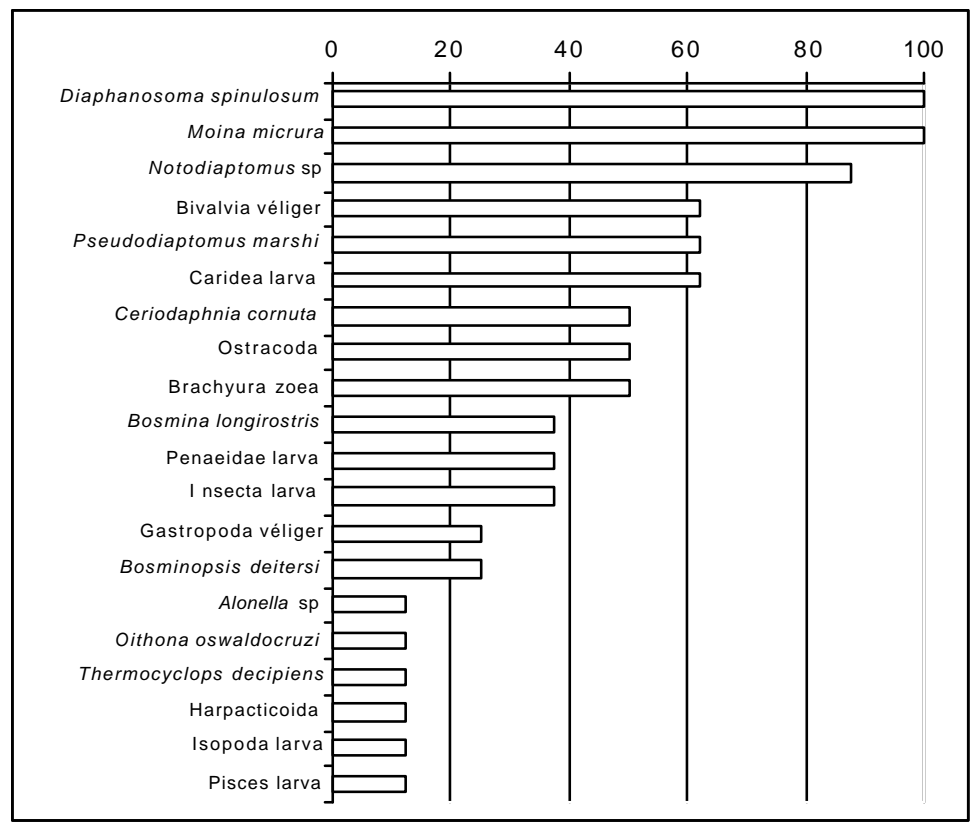

Figura 8 - Freqüência de ocorrência do macrozooplâncton no sistema estuarino do Rio São Francisco, em Brejo Grande, Sergipe, em 12 e 13/01/98 (período seco).

Trab. Oceanog. Univ. Fed. PE, Recife, 27(1): 33-54, 1999. 


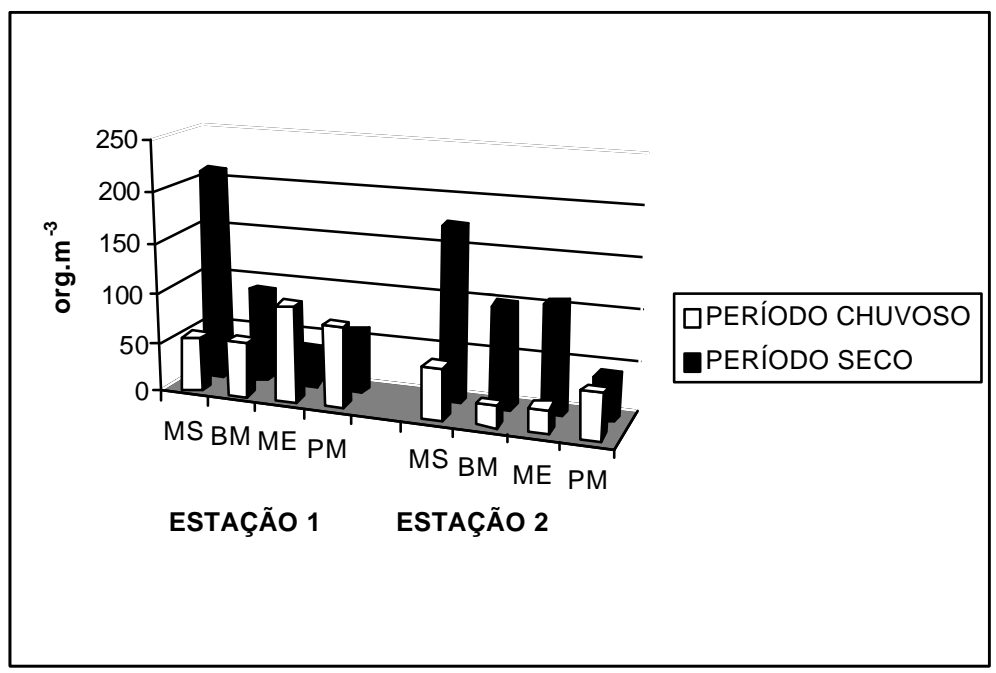

Figura 9 - Variação quantitativa total do macrozooplâncton no sistema estuarino do rio São Francisco, em Brejo Grande, Sergipe em 04 e 05/08/97 (período chuvoso) e 12 e 13/01/98 (período seco).

\section{DISCUSSÃO}

Por ser o principal rio do Nordeste brasileiro, o rio São Francisco tem sido intensamente utilizado em toda a sua extensão, para a geração de energia elétrica, irrigação, abastecimento de cidades e como receptor de resíduos orgânicos e inorgânicos das mais diversas fontes.

O Baixo São Francisco, onde se estabeleceram grandes projetos de agricultura, em várzeas drenadas e irrigadas, foi bastante impactado, restando hoje alguns monocultivos em manchas, muitos dos quais estressados. Entretanto, houve poucos estudos ambientais que avaliassem custo/benefício, principalmente na área estuarina próxima à desembocadura (Marques, 1992). Some-se a este fato a forte erosão que vem destruindo o povoado do Cabeço e algumas áreas internas do rio, próximas ao Município de Brejo Grande, em Sergipe.

Todos esses impactos causaram uma queda geral na produção pesqueira, prejudicando diretamente a comunidade de pescadores da área; contudo, não houve estudos que avaliassem essas questões.

Nas regiões estuarinas tropicais, um dos principais fatores condicionantes da comunidade zooplanctônica é a salinidade. Segundo Rao (1977), a fauna 
estuarina compreende organismos adaptados às amplas flutuações dos parâmetros estando a distribuição e abundância do plâncton intimamente associada à salinidade.

$\mathrm{Na}$ área estudada do rio São Francisco o predomínio foi do fluxo de água doce, sendo o estuário classificado como homogêneo (tipo C) no período chuvoso e fortemente estratificado na sua foz no período seco (tipo A), de acordo com o sistema esquematizado por Tundisi (1970). Esta influência limnética se faz sentir até as partes próximas à desembocadura, onde no período chuvoso chega a alcançar 0,04\% o, mesmo sendo esta época a de menor vazão (período seco à montante).

A salinidade afeta diretamente a distribuição e ocorrência do zooplâncton, que se caracterizou no rio São Francisco pelo predomínio de espécies limnéticas, muitas das quais registradas por por Neumann-Leitão e Nogueira-Paranhos (1987/1989), nas represas de Sobradinho, Paulo Afonso e Itaparica. O grupo predominante no microzooplâncton foi Rotifera. Neumann-Leitão (1986), estudando os Rotifera da área estuarina de Suape, registrou a ocorrência deste grupo, em 43\% das amostras, quase todas provenientes de locais com baixa salinidade.

Segundo Ruttner-Kolisco (1977), águas estuarinas devem ser consideradas como biótopos extremos no que concerne aos Rotifera, pois à medida que aumenta a salinidade, diminui o número de espécies. O estudo deste grupo em áreas estuarinas é de relevância, pois não só desempenham papel importante na teia alimentar, constituindo apreciável parcela do item nutricional de outros organismos, como também são indicadores de regime trófico, acidez ou alcalinidade e saprossidade (Pourriot, 1976; Koste, 1978). Rotifera foi utilizado na classificação de lagos na Estonia (Mäemets, 1983) e na Inglaterra (Pontin e Langley, 1993). O uso de Rotifera como indicador da qualidade da água foi sugerido por Gannon e Stemberg (1978) e no monitoramento ambiental por Pejler (1981).

Estudos sobre Rotifera estuarinos no Brasil são poucos, destacando-se o de Neumann-Leitão (1986) para a área estuarina de Suape-PE, onde foram identificadas 48 espécies e o de Diniz e Araújo (1992), para o estuário do rio Japaratuba-SE, com 23 espécies.

A citação de Rotifera em outros estuários brasileiros está restrita a trabalhos de zooplâncton, ressaltando-se o de Neumann-Leitão (1994) para o estuário do rio Ipojuca-PE, onde foram registradas 66 espécies e o de Silva (1994) para o estuário do rio Capibaribe-PE, onde identificaram-se 37 espécies. Nos demais trabalhos de zooplâncton, poucas espécies foram citadas ou apenas o grupo é mencionado como um todo (Matsumura-Tundisi, 1972; Tundisi et al, 1978; Santana, 1978 a e b; Paranaguá e Koening, 1980; Paranaguá e Neumann-Leitão, 1980, 1981; Pereira, 1980; Nordi, 1982; Paranaguá et al, 1982; Lansac Tôha, 1985; Lopes et al, 1986; Lopes, 1988; Roquetti-Humaytá e Carvalho, 1988; Sant'anna, 1993). Em quase todos estes trabalhos, Rotifera ocorreu durante curtos períodos, sempre em baixa salinidade.

Na composição dos Rotifera do sistema estuarino do rio São Francisco, destacaram-se as famílias Brachionidae e Lecanidae, comumente dominantes em outros estuários da região (Neumann-Leitão, 1986; 1994; Diniz e Araújo, 1992; Silva, 1994). 
Embora as famílias Brachionidae e Lecanidae tenham apresentado maior biodiversidade, em termos de distribuição e abundância, merece destaque a família Philodinidae, representada na área por Rotaria rotatoria e Rotaria sp, que, segundo Ricci (1987), são indicadoras de poluição orgânica.

Arora (1966), estudando os Rotifera como indicadores da natureza trófica dos ambientes aquáticos, relata a presença de Rotaria rotatoria em águas poluídas. Este fato evidencia que no estuário do rio São Francisco a poluição orgânica é alta, principalmente nas áreas mais próximas às cidades; isto ocorre porque as águas residuárias urbanas são lançadas no rio sem qualquer tratamento, e pelo uso direto de suas águas para higiene pessoal, para lavagem de roupas, de utensílios domésticos e de animais.

Além dos Rotifera ocorreram Copepoda, Cladocera, Protozoa, larvas de Mollusca, de Crustacea e de Pisces. De uma forma geral, a composição de espécies nos dois períodos e nas estações do rio São Francisco foi semelhante. Além disso, caracterizou-se pela baixa biomassa, o que indica local pouco produtivo.

$\mathrm{Na}$ realidade, a queda na produção pesqueira nos últimos anos, está diretamente associada ao zooplâncton, grupo ao qual pertencem as larvas de peixes, crustáceos e moluscos. Assim a falta de sucesso quando zooplanctonte resultará na queda produtiva das populações adultas.

Segundo Marques (1992), os pescadores percebem e sofrem o impacto negativo da construção das grandes barragens, dos desmatamentos, dos aterros, da irrigação e drenagem. Percebem que estes são os principais responsáveis pelo desaparecimento de espécies, pela diminuição do número do tamanho mínimo e máximo dos peixes e crustáceos.

Snedaker e Getter (1985) afirmam que os ecossistemas estuarinos têm uma assombrosa capacidade natural para manter-se e renovar-se após um distúrbio, caso sejam mantidas as características básicas do habitat que favoreceram a formação do estuário. Entretanto, distúrbios que causem mudanças nos padrões dominantes da circulação da água afetarão toda a estrutura do ecossistema, incapacitando-o de voltar ao ponto original.

Assim, o estuário do rio São Francisco foi impactado drasticamente e os estudos evidenciaram que mudanças continuaram a ocorrer e, até hoje, o ambiente ainda não conseguiu se equilibrar; pelo contrário, os impactos antrópicos continuam, pois na tentativa de resolver problemas graves que têm afetado o ambiente, mais soluções impensadas são imputadas ao meio, piorando a situação.

\section{REFERÊNCIAS BIBLIOGRÁFICAS}

ADEMA. Levantamento da flora e caracterização dos bosques de mangue do Estado de Sergipe. Aracaju, 1984a. 208 p. (Relatório).

- Estudo bio-ecológico do caranguejo-uçá e das características dos manguezais do Estado de Sergipe. Aracaju, 1984b. 107 p. (Relatório).

ANDRADE, G. O., LINS, R. C. Os climas do nordeste. In: Vasconcelos Sobrinho, J. As regiões naturais do nordeste, o meio e a civilização. Recife: CONDEPE, 1971. p.95-180. 
ARORA, H. C. Rotifera as indicators of throphic nature of environments. Hydrobiologia, The Hague, 27: p.146-159, 1966.

BITTENCOURT, A. C. S. P., MARTIN, L., DOMINGUEZ, J. M. L. et al. Evolução paleogeográfica quaternária da costa do estado de Sergipe e da costa sul do estado de Alagoas. Rev. Bras. Geoc., São Paulo, v. 13, n. 2, p. 93-97, 1983.

BOLTOVOSKOY, D. Atlas del zooplancton del Atlantico Sudoocidental y métodos de trabajos com el zooplancton marino. Mar del Plata: INIDEP,1981. 936 p.

CAVALCANTI, L. B., COELHO, P. A., KEMPF, M. et al. Shelf off Alagoas and Sergipe (Northeastern Brazil). Trabs. Inst. Oceanogr. Univ. Fed. PE., Recife, v.7/8: p. 137-150, 1965/66.

CODEVASF. Projeto semi-árido: proposta de desenvolvimento sustentável da bacia do rio São Francisco e do semi-árido nordestino. Brasília, 1996. 60 p.

COUTINHO, P. N. Sedimentation at the mouth of the São Francisco River (Brazil). Trabs. Inst. Oceanogr. Univ. Fed. PE., Recife, v. 9/8, p. 41-50, 1967/69.

DAY JR, J. W., HALL, C. A. J., KEMP, W. M. et al. Estuarine Ecology. [S. 1.]: A. Willey-Interscience Publication, 1989.

DINIZ, T. M., ARAÚJO, H. M. P. Rotifera do estuário do Rio Japaratuba. In: ENCONTRO DE ZOOLOGIA DO NORDESTE, 1992, Recife. Resumos... Recife: p. 57.

DOMingueZ, J. M. L., BITTENCOURT, A C. S. P., MARTIN, L. Esquema evolutivo da sedimentação quaternária nas feições deltaicas dos rios São Francisco (SE/AL), Jequitinhonha (BA), Doce (ES) e Paraíba do Sul (RJ). Rev. Bras. Geoc., São Paulo, v. 11, n. 4, p. 227-237, 1981.

GANNON, J. E., STEMBERGER, R. S. Zooplankton (specially crustacean and rotiferan) as indicators of water quality. Trans. Am. Micr. Soc., 91: p.16-35, 1978.

IBGE. Contagem da população 1996. Rio de Janeiro, v. 1, 1997. 724 p.

KOSTE, W. Rotatoria Die Rädertiere Mitteleuropas ein Bestimmungswerk begründet von Max Voigt. Uberordnung Monogononta, 2. Aufl. Berlin: Gebrüder Borntraeger. 1978. 637 p.

LANSAC TÔHA, F. A. Ecologia do zooplâncton do estuário do rio Una do Prelado (São Paulo - Brasil). São Paulo, 1985. 195 p. Tese (Doutorado) - Instituto Oceanográfico, Universidade de São Paulo.

LEVINGTON, J. S. Marine Biology, function, biodiversity, ecology. New york. Oxford university Press, 1995. 420p.

LOPES, R. M. Distribuição espacial do zooplâncton dos estuários da Estação Ecológica da Juréia (Peruíbe/Iguape - São Paulo). In: ENCONTRO BRASIlEIRO DE PLÂNCTON, 3., 1988, Pontal do Sul. Resumos... Pontal do Sul: p.14.

LOPES, R. M., ALMEIDA PRADO-POR, M. S., POR, F. D. Zooplankton seasonality in the Rio Verde estuary. Rev. Hydrobiol. trop., 19, (3/4), p.207-214, 1986.

MCLUSKY, D. S. The estuarine ecosystem. 2. ed. New York: Chapman \& Hall, 1989. $215 \mathrm{p}$. 
MÄEMETS, A. Rotifers as indicators of lake types in Estonia. Hydrobiologia, 104: p. 357-361, 1983.

MARQUES, José Geraldo W. (Org.) O RIMA (Relatório de Impacto Ambiental) do poder e o Contra-RIMA dos deserdados: destruição e sobrevivência da Várzea da Marituba. São Paulo: Programa de Pesquisa e Conservação de Áreas Úmidas no Brasil da Universidade de São Paulo/ IDRC/ Fundação Ford, 1992. 127 p. (Relatório preliminar)

MATSUMURA-TUNDISI, T. Aspectos ecológicos do zooplâncton da região lagunar de Cananéia com especial referência aos Copepoda (Crustacea). São Paulo, 1972. 191 p. Tese (Doutorado) - Instituto de Biociências, Universidade de São Paulo.

MELO, Fábio Vinícius Monteiro. O rio São Francisco e a percepção do espaço cotidiano. Aracaju: Núcleo de Pós-Graduação e Estudos do Semi-Árido/ PróReitoria de Pós-Graduação e Pesquisa / Universidade Federal de Sergipe, 1996. (Não paginado).

MIZUNO, T. Illustrations of the freshwater plankton of Japan. Osaka: Hoikusha, 1968. $351 \mathrm{p}$.

NEUMANN-LEITÃO, S. Sistemática e ecologia dos rotíferos (Rotatoria) planctônicos da área estuarina-lagunar de Suape-Pernambuco (Brasil). Recife, 1986. 261 p. Dissertação (Mestrado) - Departamento de Oceanografia, Centro de Tecnologia, Universidade Federal de Pernambuco.

Impactos antrópicos na comunidade zooplanctônica estuarina. Porto de Suape - PE - Brasil. São Carlos, 1994. 263 p. Tese (Doutorado), Escola de Engenharia de São Carlos, Universidade de São Paulo.

NEUMANN-LEITÃO, S., NOGUEIRA-PARANHOS, J. Zooplâncton do rio São Francisco Região Nordeste do Brasil. Trab. Oceanogr. Univ. Fed. PE, 20: 1987/1989, p.173-196.

NORDI, M. Ecologia do zooplâncton no estuário do Rio Paraíba do Norte (Paraíba-Brasil). São Carlos, 1982. 131 p. Dissertação (Mestrado) Universidade Federal de São Carlos.

PARANAGUÁ, M. N., KOENING, M. L. Composição e "standing-stock" do zooplâncton dos viveiros de criação de peixes da região de Itamaracá (PE). In: SIMPÓSIO BRASILEIRO DE AQÜICULTURA, 1., 1978 Recife. Anais..., Rio de Janeiro: p.99-107.

PARANAGUÁ, M. N., NEUMANN-LEITÃO, S., NASCIMENTO-VIEIRA, D. A. et al. Estudo ecológico da região de Itamaracá, Pernambuco, Brasil. 27. Zooplâncton de viveiros estuarinos. In: SIMPÓSIO INTERNACIONAL SOBRE UTILIZAÇÃO DE ECOSSISTEMAS COSTEIROS: PLANEJAMENTO, POLUIÇÃO E PRODUTIVIDADE. Atlântica, 5 (2): p.91, 1982.

PARANAGUÁ, M. N., NEUMANN-LEITÃO, S. Estudo ecológico da região de Itamaracá, Pernambuco. Zooplâncton dos viveiros de cultivo de peixes de Itamaracá, PE. Rev. Nordest. Biol., 3: p.187-206, 1980. Edição especial.

. Estudo ecológico da região de Itamaracá - Pernambuco - Brasil. XIII. Rotíferos planctônicos dos viveiros de cultivo de peixes. In: CONGRESSO 
BRASILEIRO DE ENGENHARIA DE PESCA, 2., 1981, Recife. Anais..., Recife: p. 233-242.

PEJLER, B. On the use of zooplankters as environmental indicators. In: M. Sudzuki (ed.). Some problems to saprobiological problems. Sanseido, Tokyo, p. 9-12, 1981.

PEREIRA, H. M. Zooplâncton do estuário do Rio Sergipe (composição e flutuação das populações). Curitiba, 1980. 130 p. Dissertação (Mestrado) - Universidade Federal do Paraná.

PONTIN, R. M., LANGLEY, J. M. The use of rotifer communities to provide a preliminary national classification of small water bodies in England. Hidrobiologia, 255/256: 411-419, 1993.

POURRIOT, R. Reflexions sur les rotiféres em tant qu'indicateurs biologiques. Separata de: Bulletin Français de Pisciculture, 48 (260): p.148-152, jan./mar., 1976.

RAO, T. S. S. Salinity and distribution of brackish warm water zooplankton in Indian estuaries. In: PROCEEDINGS OF THE SYMPOSIUM ON WARM WATER ZOOPLANKTON, 1976 Goa. Goa: National Institute of Oceanography, 1977. p. 196-204.

RICCI, C. N. Ecology of bdelloids: how to be successful. Hydrobiologia, 147: p.117-127, 1987.

ROQUETI-HUMAYTÁ, M. H., CARVALHO, M. C. Comunidade zooplanctônica do complexo lagunar Mundaú-Manguaba (Maceió, AL). In: ENCONTRO BRASILEIRO DE PLÂNCTON, 3., 1988 Pontal do Sul. Resumos..., Pontal do Sul: p. 10.

RUTTNER-KOLISKO, A. Suggestions for biomass calculation of plankton rotifers. Arch. Hydrobiol. Beih. Ergebn. Limnol., 8: p.71-76, 1977.

SANT'ANNA, E. M. E. Estrutura e biomassa da comunidade zooplanctônica da bacia do Pina (Pernambuco - Brasil), relacionadas com fatores ambientais. São Paulo, 1993. 195 p. Dissertação (Mestrado) - Escola de Engenharia de São Carlos, Universidade de São Paulo.

SANTANA, M. S. R.. Variação do plâncton em viveiro de tainha na Ilha de Itamaracá - Pernambuco. Curitiba, 1978a. 106 p. Dissertação (Mestrado) Universidade Federal do Paraná.

. Contribuição ao conhecimento do zooplâncton em viveiros de criação de tainhas Mugil curema Valenciennes, 1836. Cad. Ômega Univ. Fed. Rural de PE, 2(1): p.117-124. 1978b.

SERGIPE. Governo Estatísticas municipais: Município de Brejo Grande. Aracaju: Secretaria de Estado do Planejamento e da Ciência e Tecnologia (SEPLAN), 1997. Versão preliminar.

. Estudo de impacto ambiental da Rodovia SE-100, trecho Pirambu-foz do rio São Francisco. Aracaju: Departamento de Estradas e Rodagem (DER-SE), 1993. v.1.

SILVA, T. M. Zooplâncton do Estuário do Rio Capibaribe, Recife, PE (Brasil). Recife, 1994. Dissertação (Mestrado) - Departamento de Oceanografia, Centro de Tecnologia, Universidade Federal de Pernambuco.

Trab. Oceanog. Univ. Fed. PE, Recife, 27(1): 33-54, 1999. 
SNEDAKER, S. C., GETTER, C. D. Costas. Publ. n. 2 sobre manejo de costas. Série de Información sobre Recursos Renovables. Res. Plan. Inst. Inc. Columbia, South Carolina. 1985. 286 p.

SOUZA, M. R. M. Impactos no estuário do rio São Francisco e conseq6uências sócio-econômicas no município de Brejo Grande. Aracaju, 1998. Dissertação de Mestrado. Universidade Federal de Sergipe. 136p.

TRÉGOUBOFF, G., ROSE, M. Manuel de planctonologie Mediterranéenne. Paris: Centre Nacional de la Recherche Scientifique, 1957. 2 v.

TUNDISI, J. G. O plâncton estuarino. Contr. avulsas Inst. Oceanogr. São Paulo, sér. Ocean. Biol., 19: p.1-22, 1970.

TUNDISI, J. G., TEXEIRA, C., MATSUMURA - TUNDISI, T. et al. Plankton studies in a mangrove environment. Rev. Bras. Biol., 38: p. 301-320, 1978. 